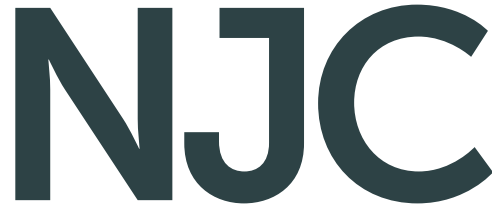

New Journal of Chemistry www.rsc.org/njc

A journal for new directions in chemistry
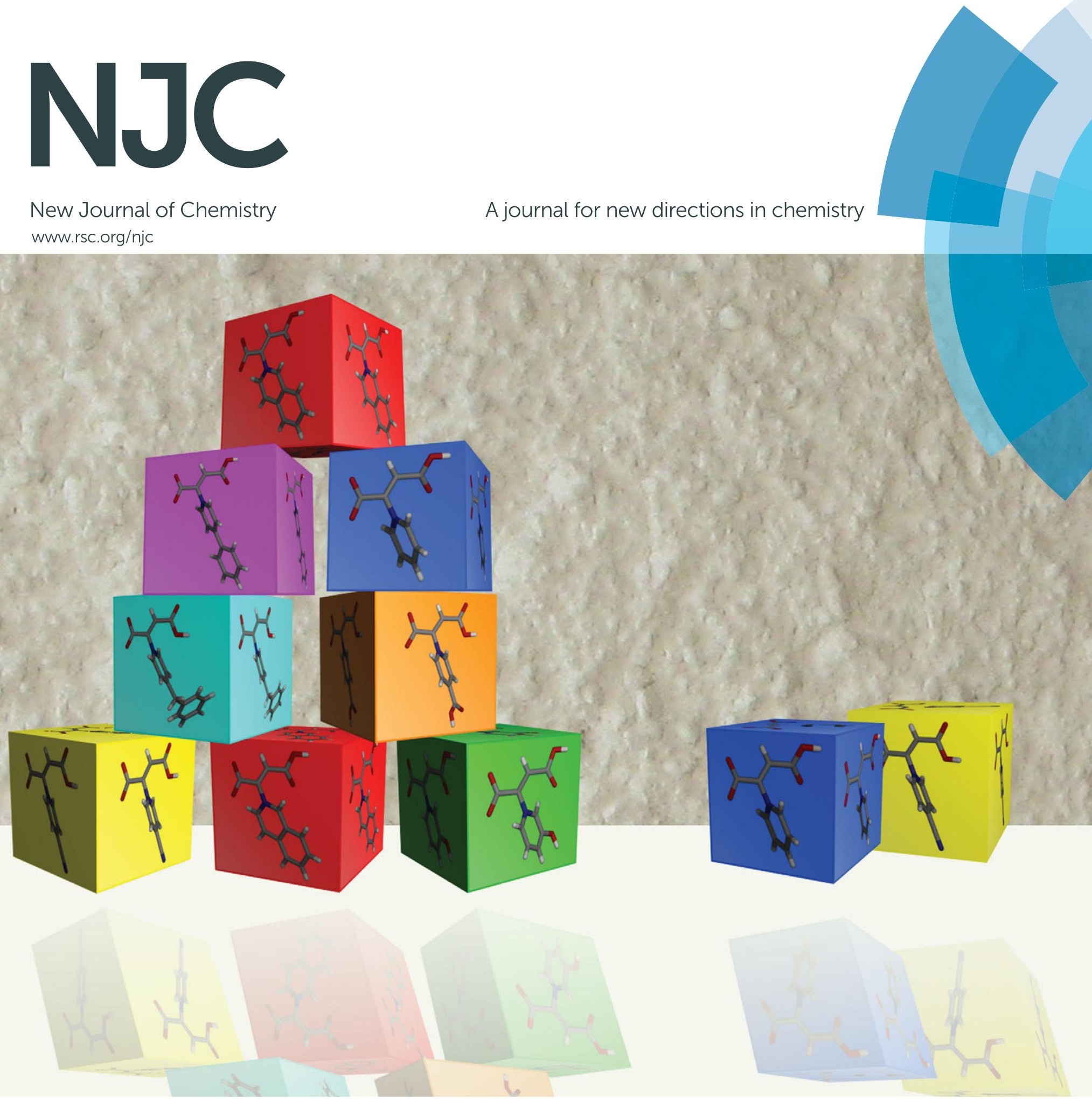

ISSN 1144-0546

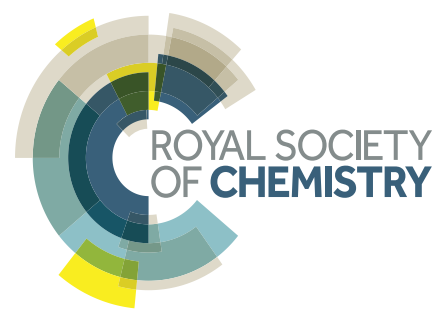


Cite this: New J. Chem., 2014 38,2778

Received (in Montpellier, France) 26th February 2014, Accepted 17th April 2014

DOI: 10.1039/c4nj00281d

www.rsc.org/njc

\title{
Synthesis and solid-state supramolecular chemistry of a series of pyridinium-derived zwitterions $\dagger$
}

\author{
Leigh Loots, * Delia A. Haynes and Tanya le Roex
}

\begin{abstract}
A new class of potential supramolecular building blocks is presented. The synthesis and crystal structures of seven novel pyridinium-derived zwitterionic compounds are discussed, as well as two related pyridinium salts. The synthesis of these compounds was achieved by simple solution methods using mild conditions, and the products were isolated as single crystals with no further purification required. Hydrogen-bonded chains were found to be prevalent in all of the crystal structures of the zwitterions and due to the robust nature of this motif, these compounds have the potential to be exploited in future supramolecular studies. There is a large scope for the synthesis of related zwitterionic compounds using a range of pyridyl substituents with varied functional groups. These zwitterionic compounds show great potential as a new class of supramolecular building block in the formation of ionic- as well as metal-organic frameworks.
\end{abstract}

\section{Introduction}

Zwitterions are well-known, particularly in biochemical processes in the form of essential amino acids. Organic synthesis involving zwitterions is also well-documented; ${ }^{1-5}$ however, the isolation of these zwitterions is often difficult as they are mostly highly reactive species that undergo further reactions. In particular, there has been a large amount of work focussed on the reaction between dimethyl acetylenedicarboxylate (DMAD) and related esters with pyridines and other N-containing heterocycles. ${ }^{1,2}$ These reactions proceed via addition of the $\mathrm{N}$-heterocycle to DMAD to form a dipolar intermediate, followed by subsequent reaction with a second equivalent of DMAD to produce a variety of heterocyclic compounds such as substituted quinolizones. ${ }^{1,2,6}$ For a more detailed account of these reactions, the in-depth review ${ }^{3}$ by Nair and colleagues should be consulted. In more recent research, the zwitterionic intermediate is most often produced en route to more complex heterocyclic compounds in multi-component reactions (MCR). ${ }^{1,2,7-10}$ The zwitterionic intermediates in these reactions are seldom isolated, as they undergo rapid reaction and/or isomerisation to yield the final target product. Reactions including Huisgen cycloadditions, ${ }^{6,11-14}$ MoritaBaylis-Hillman type reactions (MBH), ${ }^{15,16}$ Diels-Alder reactions ${ }^{3,17}$

Department of Chemistry and Polymer Science, University of Stellenbosch, P. Bag X1, Matieland, 7602, Republic of South Africa.E-mail: leighl@sun.ac.za; Fax: +27 21808 3360; Tel: +27 218083348

$\dagger$ Electronic supplementary information (ESI) available: PXRD, TGA and DSC data, NMR spectra for $\mathbf{4}$, selected hydrogen bonding tables as well as selected crystallographic data. CCDC 987540-987549. For ESI and crystallographic data in CIF or other electronic format see DOI: 10.1039/c4nj00281d and multi-component reactions ${ }^{7-10}$ have all been known to employ these acetylene-derived zwitterions.

In this study, a unique series of pyridyl-derived zwitterionic compounds have been isolated, purified and structurally characterised. The zwitterions were obtained from attempts to crystallise novel organic salts using a variety of simple acids and bases. These compounds were all obtained as single crystals by the simple reaction of acetylenedicarboxylic acid (ADC) with a selected pyridyl-derivative (Scheme 1).

To date, seven novel pyridinium-derived zwitterions have been synthesised in our laboratory by following the same simple procedure. To our knowledge, the crystal structures of only four other similar compounds have been reported in the Cambridge Structural Database (CSD) (SUCPYR10, ${ }^{18}$ SUCPYR11, ${ }^{19}$ LAQGAN $^{20}$ GOMQIP $^{21}$ and TUPWEH ${ }^{22}$ ).

Having obtained this series of compounds, together with their crystal structures, the effects of different pyridyl derivatives on the product of the reaction, as well as on the packing arrangements of these molecules in the solid state, can be examined. Because of our interest in ionic organic framework materials, ${ }^{23}$ we have

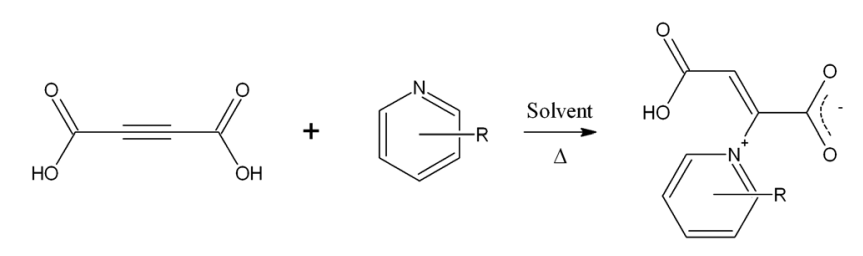

Scheme 1 The general reaction scheme for the formation of zwitterions from acetylenedicarboxylic acid and various pyridyl derivatives. 

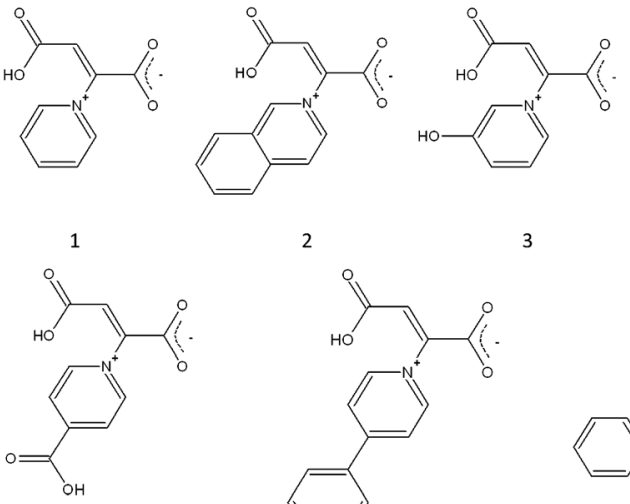

5

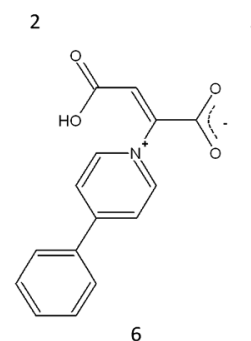

3

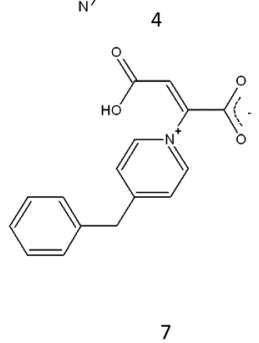

Scheme 2 The seven novel zwitterions synthesised in this study.

investigated the possibility that extending the length of the pyridyl substituent would create more space within the crystal structure, leading to the inclusion of guest molecules. The pyridyl derivatives used in this study vary in both their size (length) as well as their functional groups. The different functional groups were chosen to give insight into the effect of these factors on (1) the reaction with the acetylene group, (2) the crystal structure of the resulting zwitterion, and (3) any intermolecular interactions. Zwitterions were successfully synthesised and crystallised using the following pyridyl derivatives: pyridine (1), isoquinoline (2), 3-hydroxypyridine (3), 4-pyridinecarbonitrile (4), isonicotinic acid (5), 4-phenylpyridine (6), 4-benzylpyridine (7) (Scheme 2). This account describes the synthesis of 1-7, several of the crystal structures obtained thus far, as well as the challenges and future prospects for utilising this series of zwitterions as building blocks for solid-state framework materials.

\section{Results and discussion}

\section{Synthesis}

Whilst our initial intention with this study was to construct new cocrystals or salts from acetylenedicarboxylic acid and various pyridyl derivatives, in hindsight the formation of zwitterions should not have been completely unexpected, since acetylenic compounds are known to be highly reactive. ${ }^{24}$ What is interesting about these products is the ease with which the reactions take place, ${ }^{24}$ given the nature of the pyridyl substituent groups. A catalyst is not required, only mild reaction conditions are needed for the reaction to proceed and the product is often isolated as single crystals with no (or minimal) further purification necessary.

A similar procedure was followed for all reactions as shown in Scheme 1, varying only the solvent or solvent mixture (see Experimental section for full details). An advantage of this method of synthesis is that there is no need for any workup of the reaction, as the resulting crystalline zwitterion can simply be filtered from the solution. If necessary, the crystals can be washed with water to remove any starting material since the products are only sparingly soluble in hot water and require the addition of a base to dissolve. Most experiments were initially
Table 1 Angle between the carboxylate chain and the pyridyl moieties in compounds 1-7

\begin{tabular}{ll}
\hline Compound & Angle ${ }^{\circ}$ \\
\hline $\mathbf{1}$ & 81.50 \\
$\mathbf{2}$ & 62.72 \\
$\mathbf{3}$ & 70.89 \\
$\mathbf{4}$ & 80.99 \\
$\mathbf{5}$ & 77.20 \\
$\mathbf{6}_{\mathbf{H}_{2} \mathbf{O}}$ & 75.27 \\
$\mathbf{6}_{\mathbf{M e O H}}$ & 66.23 \\
$\mathbf{7}$ & 89.30
\end{tabular}

carried out using small quantities as test reactions, and later scaled up. Along with the seven zwitterionic compounds, two salts were also obtained during this study (5a and $\mathbf{6 a}$ ).

Because the literature reports the trapping of zwitterions using aldehydes, ${ }^{3}$ a further reaction was attempted: an excess of benzaldehyde $(10 \times)$ was added to the reaction mixture of ADC and pyridine. This did not prevent the formation of the zwitterion. Perhaps this is because a 1:1 molar ratio of acid to pyridine was used rather than only a catalytic amount of pyridine (as it is reported in the literature ${ }^{24}$ ), even though benzaldehyde was used in excess.

The majority of zwitterionic products reported in this study were obtained from para-substituted pyridyl derivatives. Ortho- and metasubstituted isomers of derivatives (see Scheme S1 in ESI $\dagger$ ) yielding 1-7 are also currently being investigated in an attempt to rationalise any directing effects that these substituents may have on the reaction.

\section{Crystal structure descriptions}

The crystal structures in this series of zwitterions share a number of common features: in each structure the nitrogen atom of the pyridyl moiety bears a positive charge, while the carboxylate group nearest to the pyridyl substituent is deprotonated, $\ddagger$ and all products obtained were shown to be the $Z$-isomer.

Each of the zwitterions has a T-shaped conformation in the solid state, and changes to the pyridyl substituent result in subtle differences in the conformations of the individual zwitterions. Twisting of these pyridyl groups to accommodate the increased steric bulk of the substituents is observed in the crystal structures of $2, \mathbf{6}_{\mathrm{MeOH}}$ and 7 . In order to quantify/investigate these differences, the angle between a plane through the carboxylate chain and a plane through the pyridyl moiety has been measured. The results are shown in Table 1. There appears to be a slight correlation between the angle and the presence of interaction between the pyridyl substituents. The outliers $2, \mathbf{6}_{\mathbf{M e O H}}, 7$ all have some weak intermolecular interactions between the pyridyl moieties $\left(2=\pi \cdots \pi, \mathbf{6}_{\mathbf{M e O H}}=\mathrm{C}-\mathrm{H} \cdots \mathrm{O}\right.$ and $\left.\pi \cdots \pi, 7=\mathrm{C}-\mathrm{H} \cdots \pi\right)$.

In all of the zwitterion crystal structures reported here, the carboxylate and carboxylic acid groups at either end of the alkyl chain hydrogen bond to one another to form one-dimensional chains. The major differences in this series of structures appear

\$ The degree of protonation was determined by measuring the $\mathrm{C}-\mathrm{O}$ bond lengths of each of the carboxylate groups $[\sim 1.2 \AA=\mathrm{C}=\mathrm{O} ; \sim 1.3 \AA=\mathrm{C}-\mathrm{O}]$ and in most cases the relevant hydrogen atoms could also be located in the electron density maps. 

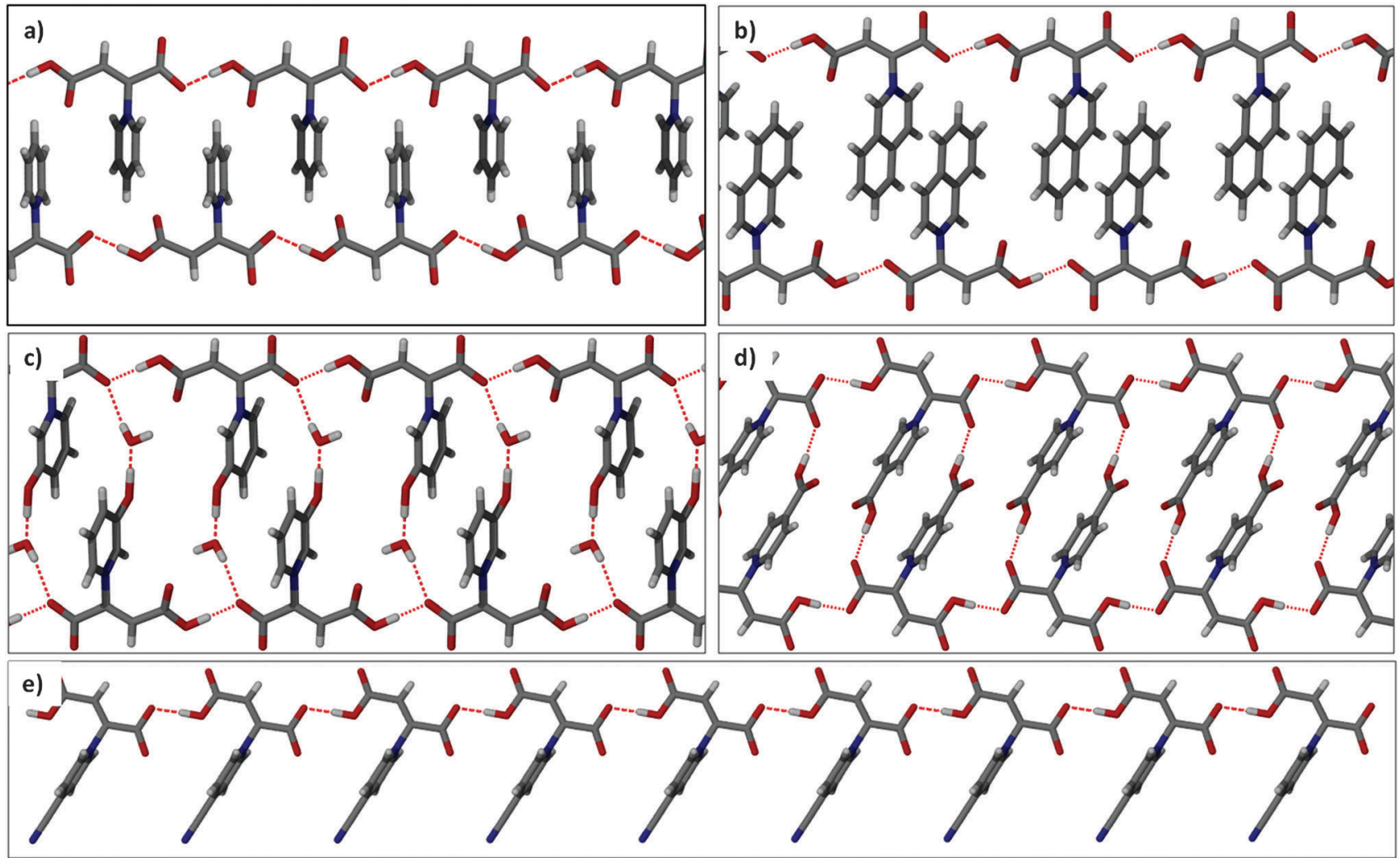

Fig. 1 One-dimensional hydrogen-bonded chains in the crystal structures $\mathbf{1}$ (a), $\mathbf{2}$ (b), $\mathbf{3}$ (c), 4 (e) and $\mathbf{5}$ (d). These chains are arranged in ladder motifs in the structures of $1,2,3$ and 5 .

in the way these chains pack together. In the majority of the crystal structures obtained, the hydrogen-bonded chains interdigitate to resemble two-dimensional ladders (Fig. 1). These ladders then pack alongside one another in an offset manner resulting in layers of ladders. The crystal structures are described in detail below, so as to highlight the differences between them.

1 crystallises in the chiral space group $P 2{ }_{1} 2_{1} 2_{1}$ with one molecule in the asymmetric unit (ASU). The ladders of hydrogen-bonded chains in the structure of $\mathbf{1}$ run along the crystallographic $a$-axis (Fig. 1a). These ladders pack in such a manner that the hydrogen-bonded chains of adjacent ladders overlap slightly (like roof tiles) to form two-dimensional layers along (001) as shown in Fig. 2. These layers then pack in an offset arrangement $(\cdots$ ABA $\cdots)$ along [001].

2 crystallises in the space group $P 2_{1} / n$ with one molecule in the ASU. Similar to the structure of $\mathbf{1}$, the isoquinolinium groups of the hydrogen-bonded chains interdigitate (Fig. 1b) but because they have a larger surface area than the pyridinium of $\mathbf{1}$, they force the one-dimensional chains to be further separated from one another (approx. $7.05 \AA$ in $1,9 \AA$ in 2 , Fig. 1b). In the structure of 2 , ladders are organised into layers along [010]. Unlike the structure of $\mathbf{1}$, the isoquinoline moieties in 2 are arranged in pairs that participate in offset $\pi \cdots \pi$ interactions (3.375 $\AA$, Fig. 3). It is evident from the results in Table 1 that the conformation of the molecule is quite different to the other zwitterions (more acute angle) and these $\pi \cdots \pi$ interactions may be a contributing factor.

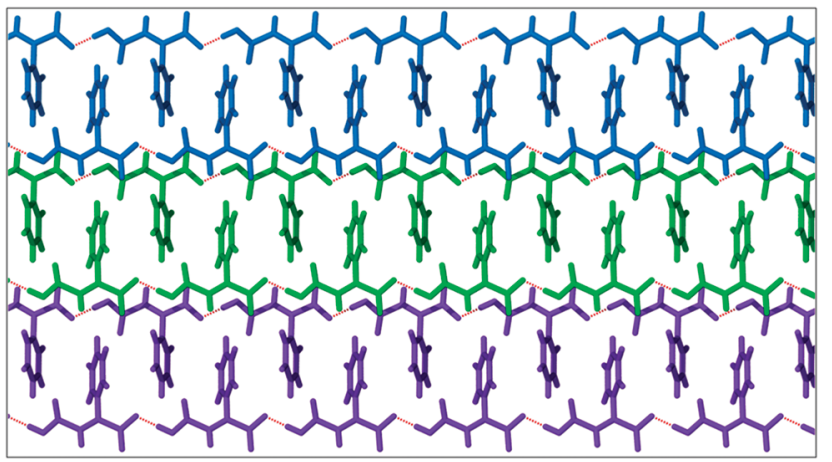

Fig. 2 Overlapping layers of unlinked ladders in the structure of 1. Different colours are used to distinguish between the individual ladder motifs.

The greater surface-area-to-volume ratio of the isoquinoline ring (compared to pyridine) may result in an increased affinity for this $\pi$-interaction. So in this instance the rungs of the ladder may be held in place by these $\pi \cdots \pi$ interactions. The two-dimensional ladders arrange in a similar manner to that observed in 1, with neighbouring hydrogen-bonded chains overlapping to give layers. However, the layers of ladders in 2 do not assemble in an offset manner but rather are stacked one on top of another along [010].

3 crystallises in the space group $P 2_{1} / c$ with one zwitterion and a water molecule in the ASU. The water molecule is situated such that it forms hydrogen bonds to both a hydroxyl group 


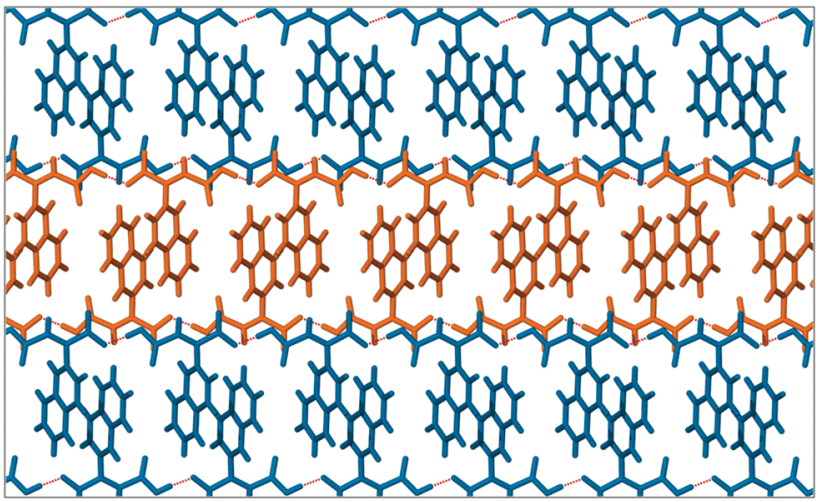

Fig. 3 The isoquinoline moieties of $\mathbf{2}$ are arranged in pairs resulting in offset $\pi \cdots \pi$ interactions within the two-dimensional ladder arrangement These ladders overlap in an analogous manner to those in $\mathbf{1}$.

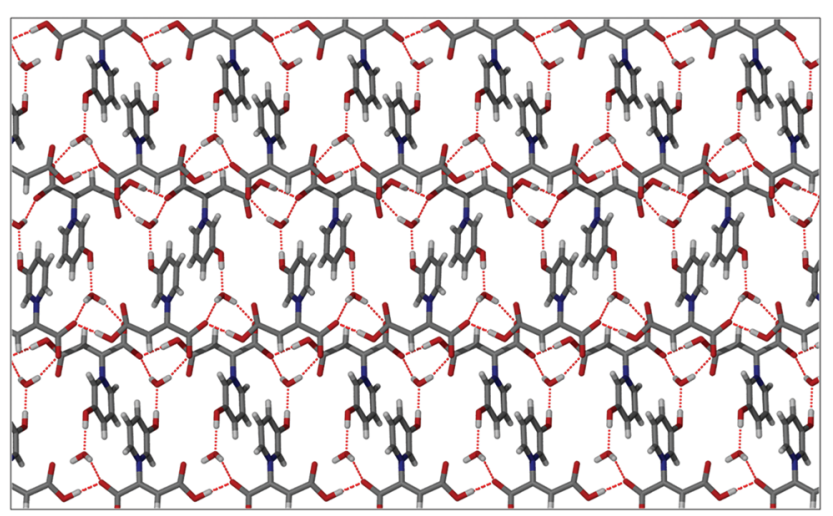

Fig. 4 The packing arrangement of 3 showing hydrogen bonding between chains to form a hydrogen-bonded ladder motif.

and a carboxylate group in the adjacent chain, resulting in a hydrogen-bonded ladder rung (Fig. 1c). The packing arrangement of $\mathbf{3}$ is similar to that found in $\mathbf{2}$; however, the overlapping one-dimensional chains are linked via hydrogen bonding between the water molecule in one ladder and the free oxygen atom of the carboxylate in the next ladder (Fig. 4). The inclusion of water allows further separation of the interdigitating carboxylate chains to approximately $9.5 \AA$, compared with that of $\mathbf{1}(7 \AA)$ and $\mathbf{2}(9 \AA)$.

4 crystallises in the monoclinic space group $P 2_{1} / c$ with one molecule in the ASU, and forms similar one-dimensional hydrogenbonded chains to those in the previous structures (Fig. 1e). However, the packing of this zwitterion is quite different to the rest of the compounds in the series. The two-dimensional assembly does not resemble a ladder, but rather two onedimensional chains run alongside each other with the cyanopyridyl moieties arranged in a herringbone pattern (Fig. 5). Other than the hydrogen bonds forming the one-dimensional chains, there are $\mathrm{C}-\mathrm{H} \cdots \mathrm{O}$ contacts between molecules in adjacent chains (Fig. 5). C-H $\cdots \mathrm{N}$ contacts are also present between nitrile moieties and an aromatic hydrogen atom in the neighbouring molecules. Each set of parallel chains are arranged at an angle of $180^{\circ}$ to the adjacent set, such that the carboxylate hydrogen-bonded chains overlap. This arrangement produces a zigzag pattern

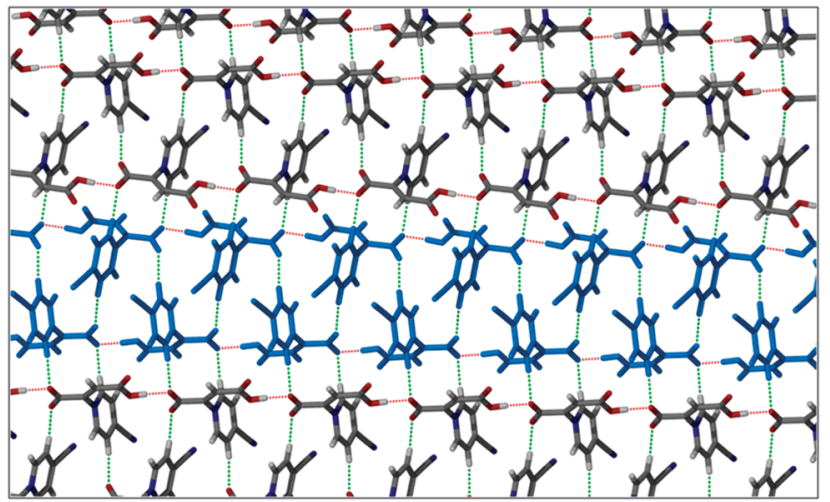

Fig. 5 Packing diagram of $\mathbf{4}$ showing the herringbone arrangement of the cyanopyridyl moieties. $\mathrm{C}-\mathrm{H} \ldots \mathrm{O}$ contacts between adjacent chains are indicated as green dotted lines. Parallel chains are indicated in blue.

along [010] forming one layer and these layers then pack one on top of another along [100] to give the three-dimensional packing arrangement.

5 crystallises in the triclinic space group $P \overline{1}$ with one whole molecule in the ASU. All three acid groups are involved in hydrogen bonding. The carboxylate and acid groups of the alkyl chain hydrogen bond to form chains along [010] (Fig. 1d). Two chains run parallel to one another (orientated $180^{\circ}$ ) and are linked through hydrogen bonding between the isonicotinate moieties and the free oxygen atoms of the carboxylate chains. This results in double rungs for the two-dimensional ladders, analogous to those seen in $\mathbf{3}$. The ladders pack in a slightly offset fashion (Fig. 6), however the carboxylate chains do not overlap as they do in all the previous structures (see above). The two-dimensional layers stack on top of one another in an offset manner such that the carboxylate chains overlap with the layer above or below, forming a staircase pattern.

A salt product (5a) was also obtained from the same components as 5. 5a crystallises in the triclinic space group $P \overline{1}$ with one 4-carboxypyridinium cation, one carboxypropynate anion and a water molecule in the ASU. The propynate anions form one-dimensional hydrogen-bonded chains along [010] with pendant carboxypyridinium cations hydrogen bonding to the

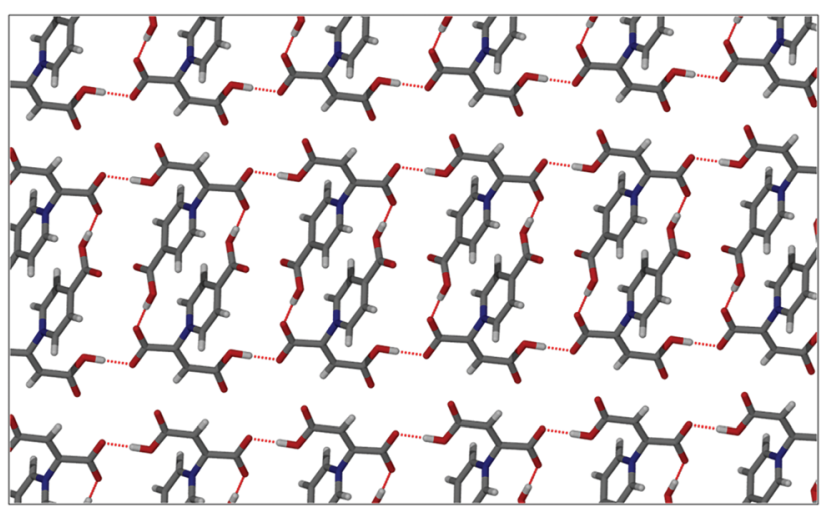

Fig. 6 Two-dimensional hydrogen-bonded ladders of $\mathbf{5}$ stack one on top of another to form layers along (001). 


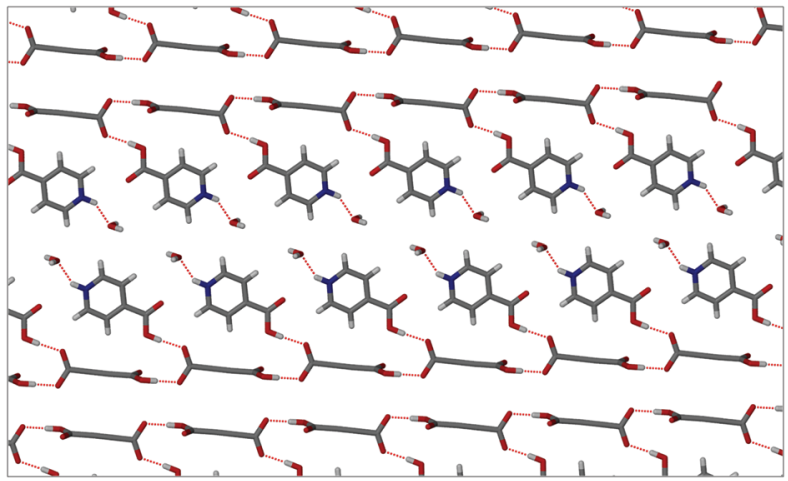

Fig. 7 One layer of $\mathbf{5 a}$ viewed down (101) showing the one-dimensional hydrogen-bonded propynate anion chains with the 4-carboxypyridinium pendant cations.

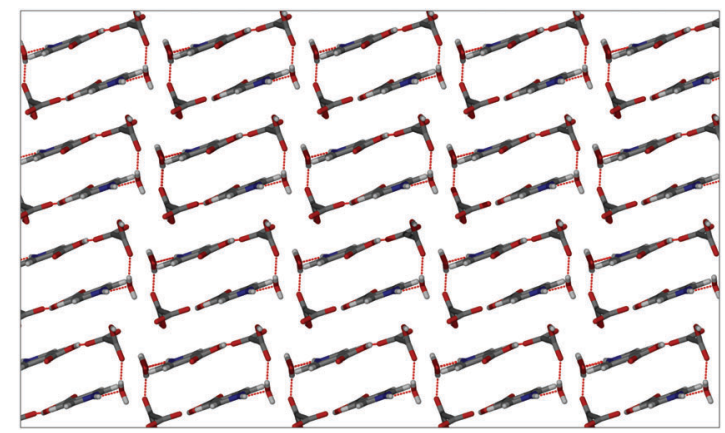

Fig. 8 Columns of 5a stacked in an offset arrangement down [010].

other oxygen atom of the carboxylate (Fig. 7). The water molecules connect two of these chains, which are stacked on top of one another, by hydrogen bonds to the pyridinium moiety and the acid group of the propynate anion. These connected chains resemble columns that pack in offset stacks (Fig. 8).

In 6 and 7 the pyridyl moiety has been extended with the addition of a phenyl (6) or a benzyl (7) substituent. This leads to less efficient packing of the zwitterions, and either small guest molecules are included or the molecules are contorted to pack more effectively. More degrees of freedom are also introduced, allowing for greater conformational flexibility.

Two crystalline solvates were obtained for compound $\mathbf{6}$, a hydrate $\left(\mathbf{6}_{\mathbf{H}_{2} \mathbf{O}}\right)$ as well as a methanol solvate $\left(\mathbf{6}_{\mathbf{M e O H}}\right)$. In addition, a salt was obtained using the same components (6a). $\mathbf{6}_{\mathrm{H}_{2} \mathrm{O}}$ crystallises in the space group $C 2 / c$ with one zwitterion molecule and three water molecules (two of which are partially occupied) in the ASU. The phenylpyridine moiety is also disordered over two positions of equal occupancy so that it appears this moiety is twisting slightly. This twisting motion is assumed to be owing to the movement of the water molecules and this is supported by thermal gravimetric analysis (TGA), which shows loss of water close to ambient temperatures (see Fig. S7, ESI $\dagger$ ). The zwitterion packs in a similar manner to that seen in 1, forming one-dimensional hydrogen-bonded chains that interdigitate to form an unconnected ladder. The partially occupied ( $42 \%$ and $28 \%$ ) water molecules (and their symmetry
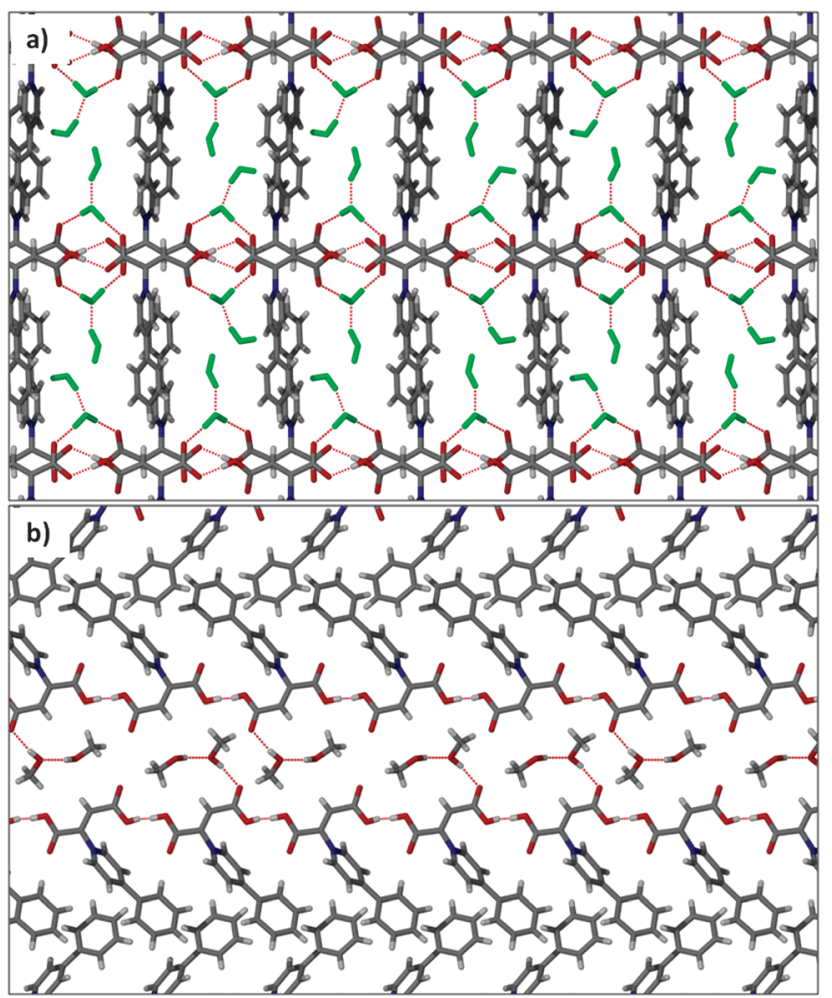

Fig. 9 Packing diagrams of (a) $\boldsymbol{6}_{\mathrm{H}_{2} \mathrm{O}}$, (b) $\boldsymbol{6}_{\mathrm{MeOH}}$ showing the differences in their packing modes. The water molecules in the structure of $\mathbf{6}_{\mathrm{H}_{2} \mathrm{O}}$ (a) are shown in green with only one of the two possible positions for the partially occupied molecules represented.

related molecules) are located between two interdigitated chains in the space alongside the phenylpyridine groups (Fig. 9a). The third water molecule is hydrogen bonded to the other two water molecules and also links two overlapping carboxylate chains.

$\mathbf{6}_{\text {MeOH }}$ crystallises in space group $P 2_{1} / n$ with one zwitterion and one molecule of methanol (disordered over two positions) in the ASU (Fig. 10). The 4-phenylpyridine moiety is disordered over two positions of equal occupancy as in the structure of $\mathbf{6}_{\mathbf{H}_{2}} \mathbf{O}$, however, it appears that there is no twisting action, but rather a sweeping motion of the phenyl ring. The sweeping motion of the phenyl ring appears to mirror the disorder positions of the methanol molecules. The hydrogen atoms of the acid moieties are also disordered over two possible positions $(55: 45)$.

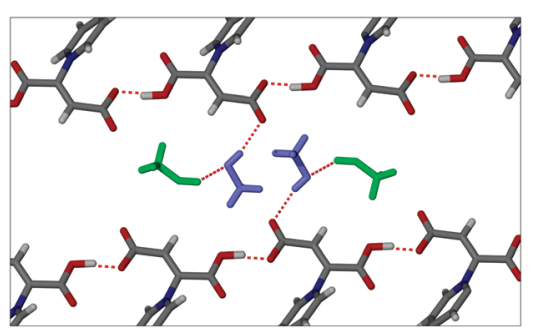

Fig. 10 Methanol molecules situated between the chains of $\mathbf{6}_{\mathrm{MeOH}}$. Molecules in blue have a higher occupancy (55\%) than those represented in green (45\%). Although there is disorder of the position of the carboxylate hydrogen atom, only the one position is shown here. 


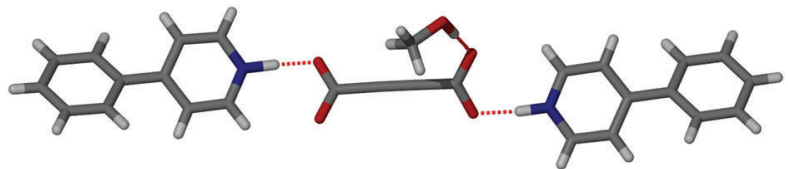

Fig. 11 The asymmetric unit of $\mathbf{6 a}$ showing the four-membered adduct.

Although analogous hydrogen-bonded chains form as in $\mathbf{6}_{\mathbf{H}_{2}} \mathbf{O}$, the structures are quite dissimilar. Rather than the hydrogenbonded chains interdigitating as in $\mathbf{6}_{\mathrm{H}_{2} \mathbf{O}}$, in $\mathbf{6}_{\mathbf{M e O H}}$ they form more of a herringbone pattern (Fig. 9b). The hydrogen-bonded carboxylate chains do not overlap but in this case are separated by the methanol molecules. The methanol molecules appear to be located in onedimensional channels that run parallel to the crystallographic $b$-axis. TG analysis (Fig. S8, ESI $\dagger$ ) confirms the presence of one methanol molecule and solvent loss commences at ambient conditions.

The salt $\mathbf{6 a}$ crystallises in the monoclinic space group $P 2_{1} / n$ with two pyridinium cations, one acetylenedicarboxylate dianion and a methanol molecule in the ASU (Fig. 11). The dianion hydrogen bonds to each of the symmetry independent pyridinium cations and the methanol hydrogen bonds to one of the free oxygen atoms to form a four-membered adduct. Phenylpyridinium cations stack one on top of another along [010]. The molecules are arranged $180^{\circ}$ to one another such that the pyridyl moiety aligns with the phenyl moiety of the next molecule in the stack. The rings are stacked slightly offset with distances between the rings of 3.683 and $3.837 \AA$.

Three different crystal structures were obtained for 7 - a close-packed structure (7), a polymorph of $7\left(7_{\text {open }}\right)$ and a 1,4-dioxane solvate $\left(7_{\text {diox }}\right)$. The synthetic details for each can be found in the Experimental section, however only the crystal structure 7 will be discussed in detail here. 7 crystallises in the space group $P b c a$ with one zwitterion molecule in the ASU. The packing arrangement of this zwitterion is remarkably different from the others in the series, although the carboxylate hydrogen-bonded chains are persistent. These chains do not form an interdigitated ladder as in all the structures described thus far. Rather, chains stack alongside one another to give anti-parallel arranged layers (Fig. 12). The layers stack on top of one another such that the pyridyl groups block the

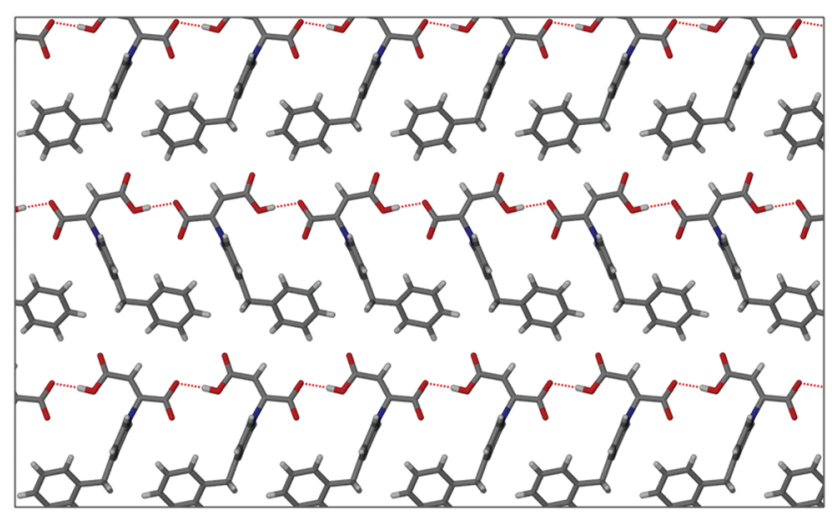

Fig. 12 A single layer of 7 showing the anti-parallel hydrogen-bonded chains. spaces created by the benzyl moiety in the neighbouring layer, resulting in bilayers. These bilayers then pack along [100] in an $\cdots$ ABCD $\cdots$ manner.

\section{Mechanochemical synthesis}

Owing to the many advantages of mechanochemical methods to prepare organic materials, reports of syntheses using these methods are becoming more prevalent in the literature, especially in the area of organic salt and cocrystal formation. ${ }^{25-32}$ It seemed plausible that mechanochemical methods may be applicable to the synthesis of zwitterions 1-7. Equimolar amounts of acetylenedicarboxylic acid and the relevant pyridyl derivative were manually ground together using a mortar and pestle. All reactions were done on a similar scale to the solution crystallisation reactions, i.e. $20 \mathrm{mg}(0.133 \mathrm{mmol}) \mathrm{ADC}$ and an equimolar amount of the pyridyl compound. Grinding of a $1: 2$ molar ratio of ADC to pyridyl compound was also investigated. Experiments were carried out neat as well as with a few drops of the same solvent used for the solution syntheses (liquid assisted grinding, LAG). Analysis of the resultant white powders by powder $\mathrm{X}$-ray diffraction (PXRD) showed that none of the products obtained matched the calculated patterns of the zwitterion compounds. It can be concluded that 1-7 cannot trivially be synthesised using mechanochemistry, however, some interesting results were obtained.

When ACD and isonicotinic acid were ground together with a few drops of the chosen solvent (neat, $\mathrm{H}_{2} \mathrm{O}$ or ethyl acetate) the result was always the same; the PXRD pattern (Fig. S15, ESI $\dagger$ ) did not match the zwitterion, but rather more closely resembles the ACD-isonicotinate salt, 5a. The grinding together of acetylenedicarboxylic acid and 4-benzylpyridine with a few drops of dioxane resulted in a colourless oil, which was suspended in enough solvent (approximately $1 \mathrm{ml}$ of dioxane/ethanol) that small crystals crashed out of solution. These crystals were subsequently analysed by single-crystal diffraction and determined to be $\mathbf{7}_{\text {open }}$, a polymorph of 7 (see Experimental section). This series of structures will be discussed in detail in a future paper.

\section{Comments and observations}

The unusual conformation of zwitterions 1-7 makes them an interesting class of molecules to study in their capacity as supramolecular building blocks. It is obvious from the crystal structures that the hydrogen bond between the carboxylate groups is a strong and reliable interaction and it is present in all zwitterion structures. The existence of this interaction means that the hydrogen-bonded chains are a strong attribute of all the structures in the series. This suggests that the differences in the packing arrangements are due to the differences in the pyridyl substituents. Most of the hydrogen-bonded chains are arranged such that they interdigitate. As the pyridyl group increases in length so the ability for these molecules to pack efficiently decreases without inclusion of guest molecules or distortion of the molecule itself in one way or another. Adding a hydrogenbond donor or acceptor to the pyridyl substituent impacts the overall structure in that there are other strong interactions that can exist. This is observed in structures $\mathbf{3}$ and $\mathbf{5}$ with the addition of a hydroxyl group (3) and a carboxylate group (5). In fact, the 
hydrogen-bonded chains in these two structures bear close resemblance to one another - hydrogen bonds extend to link two of the carboxylate chains to form two-dimensional ladders.

Because the same hydrogen-bonded chains of carboxylates were observed in all the compounds, it would be of interest to ascertain if it is possible to either extend these networks or find suitable candidates that will disrupt these networks to produce more interesting arrangements. It has been observed in the crystal structures of this series that we can extend the distance between carboxylate chains by using longer pyridyl derivatives. It would be interesting to see if it is possible to extend this even further using hydrogen bonding to another molecule - i.e. forming cocrystals or salts. From the results it is clear that increasing the length of the substituent increases the probability of guest inclusion. However, it appears that the identity of the guest is important in determining whether it will be included or not, although we cannot be certain what the requirements are. It may be as simple as a size/shape match or it could be more complicated such as polarity of the guest or whether there are stabilising interactions between host and guest.

It would also be of interest to have two different substituents on the same zwitterion. A number of mixed substituent reactions have been attempted with this goal in mind, but so far, none has yielded anything other than the singly substituted zwitterion or a salt. In one instance when 4-phenylpyridine and pyridine were combined with acetylenedicarboxylic acid, the reaction yielded a few crystals of the salt (6a) and a white precipitate. The white precipitate was identified by PXRD analysis as a mixture of $\mathbf{1}$, $\mathbf{6}_{\mathbf{H}_{2} \mathbf{O}}$ and the salt $\mathbf{6 a}$. Combining ADC with 4-phenylpyridine and pyridinecarbonitrile in a $1: 1: 1$ molar ratio in a mixture of $\mathrm{MeOH}$ and water yields a mixture of compounds 4 and 5. This begs the question: is there selectivity for one substituent over another? If this is indeed true, further reactions are required to determine which substituent is the more favoured and propose a reason for this selectivity.

Our initial objective with this study was to construct new assemblies using organic salts and cocrystals. Having serendipitously discovered these novel stable zwitterions, it seems only natural to pursue supramolecular materials using these compounds as building blocks. With these seven new zwitterions in hand, having different pyridyl substituents ranging in size and functionality, it is likely that a wide range of supramolecular architectures will be produced, owing to the unique conformation of these ions, as well as their hydrogen bonding potential. Organic as well as metal-organic materials are currently being investigated.

\section{Conclusions}

The synthesis of seven novel pyridinium zwitterionic compounds as well as two novel salts is presented. These compounds were all obtained using mild reaction conditions, without the need for a catalyst, and gave good to fair yields. Mechanochemical methods did not yield the zwitterions, but in some cases the products were identified as salts. These novel compounds show great potential as a new class of supramolecular building block in the formation of ionic- as well as metal-organic frameworks.

\section{Experimental}

\section{Methods}

Single-crystal X-ray intensity data were collected on a Bruker SMART Apex II X-ray diffractometer equipped with a Mo $(\lambda=$ $0.71073 \AA$ ) fine-focus sealed tube and a $0.5 \mathrm{~mm}$ MonoCap collimator. Data were captured with a CCD (Charge-Coupled Device) area-detector. All data collections were carried out at $100 \mathrm{~K}$ (unless otherwise stated) using an Oxford Cryosystems cryostat (700 Series Cryostream Plus) attached to the diffractometer. Data collection and reduction were carried out using the Bruker software package APEX $2,{ }^{33}$ using standard procedures. All structures were solved and refined using SHELX-2013 ${ }^{34}$ employed within the X-Seed ${ }^{35,36}$ environment. Diagrams were generated using POV-Ray. ${ }^{37}$

PXRD patterns were collected using a PANalytical X'Pert Pro diffractometer with Bragg-Brentano geometry using $\mathrm{CuK} \alpha$ radiation $(\lambda=1.5418 \AA)$ at $45 \mathrm{kV}$ and $40 \mathrm{~mA}$. Intensity data were captured with an X'Celerator detector with $2 \theta$ scans performed in the range $5-50^{\circ}$ with a 0.0167 step size. Samples were spun at 4 revolutions per second.

${ }^{1} \mathrm{H}$ and ${ }^{13} \mathrm{C}$ NMR spectra were recorded (in $\mathrm{D}_{2} \mathrm{O}$ ) with an Agilent spectrometer at $600 \mathrm{MHz}$, unless otherwise specified, at $25{ }^{\circ} \mathrm{C}$. Between $0.02-0.04 \mathrm{ml}$ of triethylamine was added to each of the samples to aid dissolution in $\mathrm{D}_{2} \mathrm{O}$ - with the exception of $\mathbf{5 a}$ and $\mathbf{6 b}$ where this was not necessary - the signals for triethylamine are not indicated in the text.

Differential Scanning Calorimetry (DSC) was carried out using a TA Instruments Q20 system under a $\mathrm{N}_{2}$ gas purge (flow rate of $50.0 \mathrm{ml} \mathrm{min}{ }^{-1}$ ) coupled to a RCS cooling unit. Samples were cycled from $-20{ }^{\circ} \mathrm{C}$ to approximately $200{ }^{\circ} \mathrm{C}$ (depending on $T_{\text {dec }}$ (TGA)) at a heating rate of $10{ }^{\circ} \mathrm{C} \min ^{-1}$ and a cooling rate of $5{ }^{\circ} \mathrm{C} \mathrm{min}^{-1}$. This was performed using non-hermetically sealed aluminium pans.

Thermogravimetric analysis was carried out using a TA Instruments Q500 system under a $\mathrm{N}_{2}$ gas purge (flow rate $50.0 \mathrm{ml} \mathrm{min}{ }^{-1}$ ) using aluminium sample pans at a ramp rate of $10{ }^{\circ} \mathrm{C} \mathrm{min}^{-1}$.

Melting point determinations were carried out using a Stuart SMP3 melting point apparatus.

\section{Synthesis}

(2Z)-3-Carboxy-1-hydroxy-2-pyridinium-1-ylprop-2-en-1-olate (1). Pyridine (PYR, $0.014 \mathrm{~g}, 0.014 \mathrm{ml}, 0.177 \mathrm{mmol}$ ) was dissolved in methanol $(1 \mathrm{ml})$, and the mixture added quantitatively to acetylenedicarboxylic acid (ADC, $0.020 \mathrm{~g}, 0.175 \mathrm{mmol}$ ) using a further $1 \mathrm{ml} \mathrm{MeOH}$. The mixture was stirred at approximately $60{ }^{\circ} \mathrm{C}$ until all the reagents had dissolved (approximately $2 \mathrm{~min}$ ). Cooling this solution to room temperature yielded crystals of 1 within a few days. The same product was obtained from a $1: 2$ acid to pyridine starting ratio. The reaction can also be scaled up 5 times (molar ratio). $80 \%$ yield, $T_{\mathrm{dec}}=200-204{ }^{\circ} \mathrm{C}$, 
$\delta_{\mathrm{H}}\left(600 \mathrm{MHz}, \mathrm{D}_{2} \mathrm{O}\right) 7.26(1 \mathrm{H}, \mathrm{s}), 8.10(2 \mathrm{H}, J=7.03 \mathrm{~Hz}, \mathrm{t}), 8.62$ $(1 \mathrm{H}, J=7.76 \mathrm{~Hz}, \mathrm{t}), 8.71(2 \mathrm{H}, J=5.57 \mathrm{~Hz}, \mathrm{~d}) ; \delta_{\mathrm{C}}\left(600 \mathrm{MHz}, \mathrm{D}_{2} \mathrm{O}\right)$ 128.15, 133.89, 140.50, 145.56, 147.54, 166.18, 169.70.

(2Z)-3-Carboxy-1-hydroxy-2-isoquinolinium-2-ylprop-2-en-1-olate (2). Isoquinoline (IQ, $0.023 \mathrm{~g}, 0.178 \mathrm{mmol}$ ) was dissolved in $1 \mathrm{ml}$ $\mathrm{MeOH}$ and transferred to a vial containing acetylenedicarboxylic acid $(0.020 \mathrm{~g}, 0.175 \mathrm{mmol})$ using a further $1 \mathrm{ml} \mathrm{MeOH}$. Water $(1 \mathrm{ml})$ was added to aid dissolution, and the mixture was heated gently with stirring until all components had dissolved. The mixture was allowed to cool to room temperature. Colourless crystals were obtained after a few weeks (once some of the solvent had been allowed to evaporate). $31 \%$ yield, $T_{\text {dec }}=183-189{ }^{\circ} \mathrm{C}, \delta_{\mathrm{H}}$ $\left(600 \mathrm{MHz}, \mathrm{D}_{2} \mathrm{O}\right) 7.33-7.35(1 \mathrm{H}, \mathrm{m}), 7.96(1 \mathrm{H}, J=14.65,1.17 \mathrm{~Hz}$, dd), 8.13-8.19 (3 H, m), 8.32-8.35 (1 H, m), $8.36(1 \mathrm{H}, \mathrm{s}), 9.58$ $(1 \mathrm{H}, \mathrm{s}) ; \delta_{\mathrm{C}}\left(600 \mathrm{MHz}, \mathrm{D}_{2} \mathrm{O}\right) 126.02,127.51,127.95,131.23,132.16$, 134.06, 135.20, 138.53, 138.59, 140.43, 150.57, 166.59, 169.95.

(2Z)-3-Carboxy-1-hydroxy-2-(3-hydroxylpyridinium-1-yl)prop-2en-1-olate (3). Acetylenedicarboxylic acid $(0.020 \mathrm{~g}, 0.175 \mathrm{mmol})$ and 3-hydroxypyridine $(3 \mathrm{OH}, 0.017 \mathrm{~g}, 0.178 \mathrm{mmol})$ were combined in a glass vial and dissolved in a mixture of ethyl acetate $(2 \mathrm{ml})$ and water $(1 \mathrm{ml})$. The solution was gently heated and stirred until the contents were completely dissolved. The vial was capped and allowed to cool. After 2 weeks the cap was removed and some of the solvent was allowed to evaporate yielding colourless crystals. $45 \%$ yield, $T_{\mathrm{dec}}=184-187{ }^{\circ} \mathrm{C}, \delta_{\mathrm{H}}(300 \mathrm{MHz}$, $\left.\mathrm{D}_{2} \mathrm{O}\right) 7.14(1 \mathrm{H}, \mathrm{s}), 7.44(1 \mathrm{H}, J=2.64,1.91 \mathrm{~Hz}, \mathrm{dd}), 7.46(1 \mathrm{H}, J=$ 2.71, $1.69 \mathrm{~Hz}, \mathrm{dd}), 7.51-7.54(2 \mathrm{H}, \mathrm{m}), 7.56(1 \mathrm{H}, J=1.61 \mathrm{~Hz}, \mathrm{t})$, $7.58(1 \mathrm{H}, J=1.54 \mathrm{~Hz}, \mathrm{t}) ; \delta_{\mathrm{C}}\left(300 \mathrm{MHz}, \mathrm{D}_{2} \mathrm{O}\right) 127.73,129.60$, 133.15, 135.13, 135.66, 139.91, 166.74, 167.16, 170.53 .

(2Z)-3-Carboxy-2-(4-cyanopyridinium-1-yl)-1-hydroxyprop-2en-1-olate (4). Acetylenedicarboxylic acid (0.020 g, $0.175 \mathrm{mmol})$ and 4-pyridinecarbonitrile (PCN, $0.018 \mathrm{~g}, 0.173 \mathrm{mmol}$ ) were combined in a glass vial in a 1:1 molar ratio. Methanol $(1 \mathrm{ml})$ and 1,4-dioxane $(1 \mathrm{ml})$ were added and the mixture was stirred and heated to approximately $60{ }^{\circ} \mathrm{C}$ to dissolve the reagents. The mixture was allowed to cool to room temperature, and colourless crystals of $\mathbf{4}$ formed within a few days. The same product was obtained when the two components were dissolved in pure methanol $(2 \mathrm{ml}) .55 \%$ yield, $T_{\mathrm{dec}}=187-190{ }^{\circ} \mathrm{C}, \delta_{\mathrm{H}}$ $\left(600 \mathrm{MHz}, \mathrm{D}_{2} \mathrm{O}\right) 6.55(2 \mathrm{H}, J=7.62 \mathrm{~Hz}, \mathrm{~d}), 7.06(1 \mathrm{H}, \mathrm{s}), 7.68$ $(2 \mathrm{H}, J=7.62 \mathrm{~Hz}, \mathrm{~d}) ; \delta_{\mathrm{C}}\left(600 \mathrm{MHz}, \mathrm{D}_{2} \mathrm{O}\right) 117.25,126.27,126.82$, $127.01,132.51,134.01,139.18,143.52$, 146.87, 150.41, 168.77, $171.55,180.71 . \S$

(2Z)-3-Carboxy-2-(4-carboxypyridinium-1-yl)-1-hydroxyprop-2-en1-olate (5). Acetylenedicarboxylic acid $(0.050 \mathrm{~g}, 0.438 \mathrm{mmol})$ was combined with isonicotinic acid (INA, $0.054 \mathrm{~g}, 0.439 \mathrm{mmol}$ ) in a glass vial and a mixture of acetonitrile $(6 \mathrm{ml})$ and water $(3 \mathrm{ml})$ was added. The solution was stirred and heated to approximately $60{ }^{\circ} \mathrm{C}$ to dissolve the reagents (approximately $5 \mathrm{~min}$ ). The mixture was allowed to cool to room temperature, and colourless block-shaped

$\S$ A colour change occurred upon addition of triethylamine to the NMR sample indicating a possible reaction occurring. This is evident in the NMR with 4 being the major component along with a minor amount of an unknown compound. Only the NMR resonances for $\mathbf{4}$ are presented here, however the full spectra are available in the ESI. $\dagger$ crystals were obtained within a few days. Different ratios of starting materials, viz. 1:2, 2:1 and 1:4, yielded the same product. Crystals were also obtained from other solvent mixtures for example methanol-water, tetrahydrofuran-water, ethyl acetatewater, 1,4-dioxane-water and water. 71\% yield, $T_{\mathrm{dec}}=200-$ $206{ }^{\circ} \mathrm{C}, \delta_{\mathrm{H}}\left(600 \mathrm{MHz}, \mathrm{D}_{2} \mathrm{O}\right) 7.26(1 \mathrm{H}, \mathrm{s}), 8.29(2 \mathrm{H}, J=$ $6.74 \mathrm{~Hz}, \mathrm{~d}), 8.77(2 \mathrm{H}, J=6.74 \mathrm{~Hz}, \mathrm{~d}) ; \delta_{\mathrm{C}}\left(600 \mathrm{MHz}, \mathrm{D}_{2} \mathrm{O}\right)$ 126.72, 133.94, 140.42, 146.31, 154.29, 166.09, 169.27, 169.67.

A salt of acetylenedicarboxylic acid and isonicotinic acid (5a) is obtained reliably by mechanochemical methods - ADC $(0.020 \mathrm{~g}, 0.133 \mathrm{mmol})$ was ground together with INA $(0.016 \mathrm{~g}$, $0.130 \mathrm{mmol}$ ) and a suitable solvent (water or ethyl acetate) in a mortar and pestle for approximately 5-10 min. 5a can also be isolated from the solution mixture (water-EtOAc) prepared for 5 - colourless crystals are obtained from this mixture within a few hours. Minor amounts of $\mathbf{5}$ are observed in the NMR of 5a as indicated. $T_{\mathrm{mp}}=132-137{ }^{\circ} \mathrm{C} ; \delta_{\mathrm{H}}\left(600 \mathrm{MHz}, \mathrm{D}_{2} \mathrm{O}\right) 7.25$ $(2 \mathrm{H}, \mathrm{s}-5), 7.69(2 \mathrm{H}, J=6.15 \mathrm{~Hz}, \mathrm{~d}), 8.28(2 \mathrm{H}, J=6.44 \mathrm{~Hz}$, $\mathrm{d}-5), 8.55(2 \mathrm{H}, J=6.15 \mathrm{~Hz}, \mathrm{~d}), 8.76(2 \mathrm{H}, J=6.74 \mathrm{~Hz}, \mathrm{~d}-5) ; \delta_{\mathrm{C}}$ $\left(600 \mathrm{MHz}, \mathrm{D}_{2} \mathrm{O}\right)$ 76.41, 123.77, 126.71 (5), 133.93 (5), 145.98, 146.31 (5), 149.85, 160.33, 173.68.

(2Z)-3-Carboxy-1-hydroxy-2-(4-phenylpyridinium-1-yl)prop-2en-1-olate (6). 6 was obtained by combining acetylenedicarboxylic acid (0.020 g, $0.175 \mathrm{mmol})$ and 4-phenylpyridine (4PP, $0.027 \mathrm{~g}, 0.174 \mathrm{mmol})$ in methanol $(2 \mathrm{ml})$. The solution was gently heated to approximately $60{ }^{\circ} \mathrm{C}$ with stirring, the vials were capped and left to cool. Colourless crystals were obtained within a few days and determined to be a methanol solvate $\left(\mathbf{6}_{\mathbf{M e O H}}\right)$. Using an ethyl acetate $(2 \mathrm{ml})$-water $(1 \mathrm{ml})$ mixture yielded crystals of a hydrate of $6\left(\mathbf{6}_{\mathbf{H}_{2} \mathrm{O}}\right) \cdot 53 \%$ yield, $T_{\mathrm{mp}}\left(\mathbf{6}_{\mathrm{MeOH}}\right)$ 174-177 ${ }^{\circ} \mathrm{C}, T_{\mathrm{mp}}\left(6_{\mathrm{H}_{2} \mathrm{O}}\right){ }_{180-182}{ }^{\circ} \mathrm{C}, \delta_{\mathrm{H}}\left(600 \mathrm{MHz}, \mathrm{D}_{2} \mathrm{O}\right) 7.28$ $(1 \mathrm{H}, \mathrm{s}), 7.54(2 \mathrm{H}, J=7.62 \mathrm{~Hz}, \mathrm{~d}), 7.58(1 \mathrm{H}, J=7.03 \mathrm{~Hz}, \mathrm{~d}), 7.82$ $(2 \mathrm{H}, J=7.62 \mathrm{~Hz}, \mathrm{~d}), 8.20(2 \mathrm{H}, J=7.03 \mathrm{~Hz}, \mathrm{~d}), 8.61(2 \mathrm{H}, J=$ $6.45 \mathrm{~Hz}, \mathrm{~d}) ; \delta_{\mathrm{C}}\left(600 \mathrm{MHz}, \mathrm{D}_{2} \mathrm{O}\right) 124.59,128.76,130.39,133.26$, 134.00, 134.08, 139.83, 145.26, 157.91, 166.45, 169.96 .

In the presence of pyridine, the reaction yields a salt (6a) of 4-phenylpyridine and acetylenedicarboxylic acid that crystallises as a methanol solvate. $T_{\mathrm{dec}}=105-110{ }^{\circ} \mathrm{C}, \delta_{\mathrm{H}}\left(600 \mathrm{MHz}, \mathrm{D}_{2} \mathrm{O}\right)$ $7.46(2 \mathrm{H}, J=7.62 \mathrm{~Hz}, \mathrm{t}), 7.51(1 \mathrm{H}, J=7.03 \mathrm{~Hz}, \mathrm{~d}), 7.69(2 \mathrm{H}$, $J=7.62 \mathrm{~Hz}, \mathrm{~d}), 8.04(2 \mathrm{H}, J=6.45 \mathrm{~Hz}, \mathrm{~d}), 8.56(2 \mathrm{H}, J=7.03 \mathrm{~Hz}, \mathrm{~d})$; $\delta_{\mathrm{C}}\left(600 \mathrm{MHz}, \mathrm{D}_{2} \mathrm{O}\right) 76.29,124.60,128.40,130.24,132.69,134.46$, 141.48, 145.16, 158.08, 160.11 .

If the crystals of the methanol solvate $\left(\mathbf{6}_{\mathbf{M e O H}}\right)$ are filtered off and left to dry in air, the crystals convert to the hydrate. When the filtrate obtained in this way is allowed to evaporate, a different product is obtained - the decarboxylation product, 6b (Scheme 3), which crystallises with one molecule each of the starting materials as well as water.

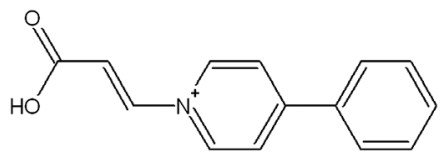

Scheme 3 Chemical structure of the decarboxylation product (6b) obtained upon evaporation of the filtrate of $\mathbf{6}_{\mathrm{MeOH}}$. 
(2Z)-2-(4-Benzylpyridinium-1-yl)-3-carboxy-1-hydroxyprop-2-en1-olate (7). 7 was obtained by heating a mixture of acetylenedicarboxylic acid (0.020 g, $0.175 \mathrm{mmol})$ and 4-benzylpyridine (4BP, $0.030 \mathrm{~g}, 0.177 \mathrm{mmol}$ ) to approximately $60{ }^{\circ} \mathrm{C}$, with stirring, in 1,4-dioxane and then immersing the resulting crystals $\left(7_{\text {diox }}\right)$ in $\mathrm{MeOH}$. A polymorph of 7 ( $\left.7_{\text {open }}\right)$ was obtained by preparing the same mixture in either acetone or tetrahydrofuran or by exposing the dioxane solvate $\left(7_{\text {diox }}\right)$ to air for 3 weeks. Between $59-80 \%$ yield was obtained for $7_{\text {diox }}$ and $46 \%$ yield for $7_{\text {open }}, T_{\text {dec }}(7)=$ 178-181 ${ }^{\circ} \mathrm{C}, \delta_{\mathrm{H}}\left(7_{\text {diox }}\right)$ (600 MHz, $\left.\mathrm{D}_{2} \mathrm{O}\right) 3.72$ (2 H, s, Dioxane), $7.25(1 \mathrm{H}, \mathrm{s}), 7.33(2 \mathrm{H}, J=7.62 \mathrm{~Hz}, \mathrm{~d}), 7.35(1 \mathrm{H}, J=7.62 \mathrm{~Hz}, \mathrm{~d})$, $7.40(2 \mathrm{H}, J=7.62 \mathrm{~Hz}, \mathrm{~d}), 7.42(\mathrm{~s}), 7.87(2 \mathrm{H}, J=7.03 \mathrm{~Hz}, \mathrm{~d}), 8.51$ $(2 \mathrm{H}, J=7.03 \mathrm{~Hz}, \mathrm{~d}) ; \delta_{\mathrm{C}}\left(600 \mathrm{MHz}, \mathrm{D}_{2} \mathrm{O}\right) 67.19$ (Dioxane), 127.95, 128.14 , 129.88, 130.15, 133.90, 137.40, 139.95, 144.80, 164.03, 166.40, 169.88 .

\section{Acknowledgements}

The authors would like to thank the Claude Leon Foundation, the National Research Foundation of South Africa and Stellenbosch University for funding. This material is based upon work supported financially by the National Research Foundation. Any opinion, findings and conclusions or recommendations expressed in this material are those of the author(s) and therefore the NRF does not accept any liability in regard thereto.

\section{Notes and references}

1 R. M. Acheson, in Advances in Heterocyclic Chemistry, ed. A. R. Katritzky, Academic Press, 1963, pp. 125-165.

2 R. M. Acheson and N. F. Elmore, in Advances in Heterocyclic Chemistry, ed. A. R. Katritzky and A. J. Boulton, Academic Press, 1979, pp. 263-482.

3 V. Nair, R. S. Menon, A. R. Sreekanth, N. Abhilash and A. T. Biju, Acc. Chem. Res., 2006, 39, 520-530.

4 V. Nair, C. Rajesh, A. U. Vinod, S. Bindu, A. R. Sreekanth, J. S. Mathen and L. Balagopal, Acc. Chem. Res., 2003, 36, 899-907.

5 E. Winterfeldt, Angew. Chem., Int. Ed. Engl., 1967, 6, 423-434.

6 V. Nair, A. R. Sreekanth, A. T. Biju and N. P. Rath, Tetrahedron Lett., 2003, 44, 729-732.

7 M. Piltan, I. Yavari and L. Moradi, Chin. Chem. Lett., 2013, 24, 979-983.

8 Y. Xin, J. Zhao and S. Zhu, J. Fluorine Chem., 2012, 133, 97-101.

9 M. Ghandi and N. Zarezadeh, Tetrahedron, 2013, 69, 8668-8674.

10 A. Shaabani, A. H. Rezayan, A. Sarvary, M. Heidary and S. W. Ng, Tetrahedron, 2009, 65, 6063-6068.
11 V. Nair, A. R. Sreekanth, N. Abhilash, M. M. Bhadbhade and R. C. Gonnade, Org. Lett., 2002, 4, 3575-3577.

12 V. Nair, A. R. Sreekanth and A. U. Vinod, Org. Lett., 2001, 3, 3495-3497.

13 V. Nair, S. Devipriya and S. Eringathodi, Tetrahedron Lett., 2007, 48, 3667-3670.

14 V. Nair, B. Rema Devi and L. R. Varma, Tetrahedron Lett., 2005, 46, 5333-5335.

15 P. Langer, Angew. Chem., Int. Ed., 2000, 39, 3049-3052.

16 D. Basavaiah, A. J. Rao and T. Satyanarayana, Chem. Rev., 2003, 103, 811-892.

17 O. Diels and K. Alder, Liebigs Ann. Chem., 1932, 498, 16-49.

18 M. N. G. James and M. Matsushima, Acta Crystallogr., 1976, A32, 959-961.

19 M. Padmanabhan, J. C. Joseph, A. Thirumurugan and C. N. R. Rao, Dalton Trans., 2008, 2809-2811.

20 G. Millán Corrales, D. Morales-Morales, S. HernándezOrtega, J. J. Campos-Gaxiola and A. Cruz Enríquez, Acta Crystallogr., 2012, E68, 0853.

21 S. A. Reeb, M. C. Shields and K. A. Wheeler, Acta Crystallogr., 2009, E65, o1424.

22 V. Stilinović, L. Frkanec and B. Kaitner, Acta Crystallogr., 2010, E66, o1427.

23 H. Wahl, D. A. Haynes and T. le Roex, Chem. Commun., 2012, 48, 1775-1777.

24 L. Moafi, S. Ahadi, H. R. Khavasi and A. Bazgir, Synthesis, 2011, 1399-1402.

25 A. Delori, T. Friščić and W. Jones, CrystEngComm, 2012, 14, 2350-2362.

26 T. Friščić, Chem. Soc. Rev., 2012, 41, 3493-3510.

27 T. Friščić, S. L. Childs, S. A. A. Rizvi and W. Jones, CrystEngComm, 2009, 11, 418-426.

28 T. Friščić, L. Fábián, J. C. Burley, W. Jones and W. D. S. Motherwell, Chem. Commun., 2006, 5009-5011.

29 S. Karki, T. Friščić and W. Jones, CrystEngComm, 2009, 11, 470-481.

30 S. Karki, T. Friščić, W. Jones and W. D. S. Motherwell, Mol. Pharmaceutics, 2007, 4, 347-354.

31 S. Marivel, D. Braga, F. Grepioni and G. I. Lampronti, CrystEngComm, 2010, 12, 2107-2112.

32 A. V. Trask, D. A. Haynes, W. D. S. Motherwell and W. Jones, Chem. Commun., 2006, 51-53.

33 Bruker, Bruker AXS Inc., Madison, Wisconsin, USA, 2012.

34 G. M. Sheldrick, Acta Crystallogr., 2008, A64, 112-122.

35 L. J. Barbour, J. Supramol. Chem., 2001, 1, 189-191.

36 J. L. Atwood and L. J. Barbour, Cryst. Growth Des., 2003, 3, 3-8.

37 POV-Ray for Windows, Version 3.6.1a.icl8.win32, Persistence of Vision Team, Persistence of Vision Pty. Ltd., 2003-2004. 